\title{
Evaluation of aflatoxin and Aspergillus sp. contamination in raw peanuts and peanut- based products along this supply chain in Malaysia
}

\begin{abstract}
The peanut supply chain in Malaysia is dominated by three main stakeholders (importers, manufacturers, retailers). The present study aimed to determine the levels and critical points of aflatoxin and fungal contamination in peanuts along the supply chain. Specifically, two types of raw peanuts and six types of peanut-based products were collected $(\mathrm{N}=178)$. Samples were analysed for aflatoxins by using high-performance liquid chromatography. Results revealed that the aflatoxin contamination was significantly higher $(\mathrm{P} \leq 0.05)$ in raw peanuts and peanut-based products from the retailers. However, there was no significant difference $(P \geq 0.05)$ in fungal contamination for both types of peanuts except for the total fungal count in raw peanuts from the retailers. Furthermore, raw peanut kernels from the retailers were the most contaminated ones ranged from <LOD to $1021.4 \mu \mathrm{g} / \mathrm{kg}$ (mean: 120.7 $\mu \mathrm{g} / \mathrm{kg}$, median: $1.4 \mu \mathrm{g} / \mathrm{kg}$ ) followed by the samples collected from the manufacturers which was ranged from < LOD to $181.9 \mu \mathrm{g} / \mathrm{kg}$ (mean: $20.5 \mu \mathrm{g} / \mathrm{kg}$, median: $0.0 \mu \mathrm{g} / \mathrm{kg}$ ). About $38 \%$ and $22 \%$ of the samples from the retailers and manufacturers were found to have exceeded the Malaysian Regulation limit (raw peanuts:15 $\mu \mathrm{g} / \mathrm{kg}$; peanut-based products:10 $\mu \mathrm{g} / \mathrm{kg}$ ), respectively. In contrast, no aflatoxins were detected in samples from the importers. On the other hand, $15.0 \%$ and $5.9 \%$ of peanut-based products from retailers and manufacturers, respectively, were found to have exceeded the limit. Fungal contamination (0.3-3.6 log $\mathrm{CFU} / \mathrm{g})$ was relatively higher in raw peanuts compared to that of peanut-based products $(0.6-$ $2.7 \log \mathrm{CFU} / \mathrm{g}$ ). In conclusion, the manufacturers and retailers were the critical points for aflatoxin contamination in peanuts. However, fungal contamination was more critical in the raw peanuts compared to peanut-based products. The study was limited by a minimal number of samples from the importer. Therefore, further investigations on a larger sample size should be conducted to confirm the findings in this present study.
\end{abstract}

Keyword: Peanuts; Aflatoxins; Aspergillus sp; Peanut supply chain 